\title{
EL ENIGMA, ¿ESTRATEGIA O AUTENTICIDAD?: UNA APROXIMACIÓN A LA NARRATIVA DE SILVINA OCAMPO
}

\author{
THE ENIGMA, ¿STRATEGY OR AUTHENTICITY?: \\ AN APPROACH TO SILVIA OCAMPO'S NARRATIVE
}

\section{DANIELA DÍAZ LARRALDE*}

\section{RESUMEN}

En esta investigación se pretende reflexionar en torno a algunos aspectos que caracterizan la escritura de Silvina Ocampo y que en su momento parecen ser estrategias de la autora para legitimar su proyecto creador ante el canon, pero no a partir de aceptar los parámetros que éste impone, sino de construir unos que permitan acercarse más a la expresión propia del sujeto femenino, de la mujer. Lo fragmentario, lo disruptivo, el silencio, el enigma son elementos que entran en juego y desde los que la autora no sólo construye en su narrativa personajes que proponen líneas de fuga ante cualquier intento de imposición (impostura) identitaria, sino que erige ella misma su particular condición de escritora. Así, los bordes entre ficción y realidad se hacen difusos y el enigma como estrategia parece revelarse como autenticidad.

Palabras clave: Silvina Ocampo, identidad, devenir animal, canon, legitimación.

\section{ABSTRACT}

The aim of this research is to reflect on some aspects that characterize Silvina Ocampo's writing, aspects that seem to function as Ocampo's strategies to legitimize her creative project before the canon, although not through the acceptance of parameters that the canon imposes but through building new ones that allow approaching the expression proper of the feminine subject, the woman. The fragmentary, the disruptive, the silence, the enigma are elements that come into play in her writing and from which not only does she configure characters that embody lines of flight in the face of

* Magíster en Literatura Latinoamericana (USB). Departamento de Lengua y Literatura, División de Ciencias Sociales, Universidad Simón Bolívar. Caracas, Venezuela. Correo electrónico: danydiazlarralde@gmail.com 
any imposition (imposture) of identities, but also herself in her peculiar condition as a writer. Thus, the limits between fiction and reality become blurred and the enigma as a strategy seems to reveal itself as authenticity.

Keywords: Silvina Ocampo, identity, becoming-animal, canon, legitimization.

Recibido: 16.05.13. Aceptado: 10.11.15.

Quien no me sigue allí me perderá.

Quien no me busca allí no arrancará

Una sola respuesta de mis labios.

Silvina Ocampo "Cuando perdida vago"

$\int$

N su LiBRo Kafka. Por una literatura menor (1987), Gilles Deleuze y

Félix Guattari proponen como noción que permite acercarse a la na-

rrativa del autor checo el devenir animal. $\mathrm{Al}$ respecto, afirman que:

El devenir animal no tiene nada de metafórico [...] Es un conjunto de estados, diferentes todos entre sí, injertados en el hombre en la medida en que éste busca una salida. Es una línea de fuga creadora que no quiere decir nada que no sea ella misma. (56).

Y a partir de esta categoría proponen la posibilidad de lo que podría considerarse una alternativa, una línea de fuga ante la rigidez de las formas impuestas, no sólo en lo que se refiere a la operatividad del saber, sino también a la identidad como convención social que se impone a través de la palabra. Una salida, una desterritorialización que no busca un cambio de estado, de significación, de grado, sino que es en sí misma su propia expresión.

Ciertamente, son muchas las distancias geográficas y culturales que separan la escritura de Franz Kafka de la narrativa de la argentina Silvina Ocampo, sin embargo es posible reconocer, dentro de la obra de esta cuentista, algunos personajes que responden a un proceso de des-sujeción que podría comprenderse a partir de esta noción de "devenir animal", entre otras cosas, porque se trata de personajes femeninos que se resisten, voluntaria o involuntariamente, a ser encasillados en cualquiera de los distintos moldes de feminidad disponibles para la mujer latinoamericana de mediados del siglo XX. Estos personajes generan además nuevas posibilidades de expresión que permiten repensar el vínculo entre palabra e identidad.

Es importante recordar que el cuento como género tiene una larga histo- 
ria en Argentina y que su auge se gestó, precisamente, en los años cuarenta. La mayor parte de la obra de Silvina Ocampo se inscribe en ese momento de la literatura, al igual que la escritura de su gran amigo Jorge Luis Borges y la de su esposo Bioy Casares. Sin embargo, la narrativa de esta autora es muy distinta a la de sus pares masculinos, con quienes compartió muy de cerca la vida, la palabra y el amor por la literatura, a pesar de que hoy en día -casi de manera inexplicable- no cuentan con el mismo apoyo editorial ni gozan del mismo renombre.

Desde el punto de vista formal, por ejemplo, el lector no encuentra en la narrativa de Ocampo esa coherencia estructural propia de los cuentos de Borges, en los que la trama parece estar construida con sumo detalle y delicadeza, con una esmerada lógica narratológica muy próxima a los preceptos aristotélicos y limitada a un centro donde, generalmente, se esconde un secreto. En su lugar, Silvina Ocampo entreteje historias que se van fragmentando a través de la escritura hasta convertir toda presencia en ausencia. No son historias construidas sistemáticamente, desde la razón, desde el logos de lo masculino, sino que más bien parecen ser una suerte de incursión en el ámbito ambiguo e impreciso del sueño y la emoción, espacios atribuidos histórica y culturalmente a lo femenino ${ }^{1}$. Una escritura rasgada que deja entrever o intuir el misterio a través de sus espacios de fractura, al jugar constantemente con los dos lados del espejo. Esta apertura hacia lo irreal desde lo real crea entre ambos espacios un flujo de intercambio que opera indistintamente en las dos direcciones, desrealizando lo que es real y otorgando realidad a lo fantástico y al sueño.

Ocampo parece entonces apropiarse del género fantástico para expresar una problemática real enmascarada detrás del delirio, de la locura y del sueño. Si se piensa este fenómeno como una estrategia de la autora para ingresar en los espacios de poder que establece el canon, además de la noción

\footnotetext{
${ }^{1}$ Aunque en un principio, esta repartición de atributos pareciera obedecer a la heterodesignación masculina, existe una buena cantidad de estudiosas del género que se han posicionado sobre la misma para edificar una identidad sólida y diferenciada a partir de la cual funcionar en sociedad. Carmen Elejabeitia, en Liberalismo, marxismo y feminismo (1987), indica que: "Para Lucy Irigaray esa libido distinta, más fuerte de la mujer y que por serlo el hombre oprime y somete, determina en la mujer unas capacidades específicas igualmente reprimidas: frente a la racionalidad y el discurso masculino está la sensibilidad y la irracionalidad femenina. Tomando de Lacan su consideración de que el inconsciente está estructurado en forma de lenguaje, Irigaray aplica idéntica estructura a la irracionalidad de la mujer, quien ha de encontrar su propia forma de expresarla para poderse oponer así al discurso masculino" (Elejabeitia, 1987, p. 231). Se podría hablar de un proceso de agenciamiento de la irracionalidad que si bien es más frecuente dentro de las estudiosas de género, también se trasluce en algunas ficciones escritas por mujeres latinoamericanas.
} 
de "devenir animal" es necesario tener en cuenta la reflexión que Michel Foucault ofrece, en torno a la locura, en El orden del discurso (1992). Allí este autor plantea la oposición entre razón y locura como un mecanismo de separación y rechazo que sitúa al loco, a la palabra del loco, en un espacio ambiguo, pues o bien se la considera despojada de todo sentido, de todo valor, caso en el cual la palabra se torna irrisoria, hueca; o bien se la considera peligrosa en el sentido de reveladora de una verdad que sería mejor no escuchar, no confrontar.

Desde la más alejada Edad Media -señala Foucault-, el loco es aquél cuyo discurso no puede circular como el de los otros: llega a suceder que su palabra es considerada como nula y sin valor, no conteniendo ni verdad ni importancia, no pudiendo testimoniar ante la justicia, no pudiendo autentificar una partida o un contrato, no pudiendo ni siquiera, en el sacrificio de la misa, permitir la transubstanciación y hacer del pan un cuerpo; en cambio suele ocurrir también que se le confiere, opuestamente a cualquier otra, extraños poderes, como el de enunciar una verdad oculta, el de predecir el porvenir, el de ver en su plena ingenuidad lo que la sabiduría de los otros no puede percibir. Resulta curioso constatar que en Europa, durante siglos, la palabra del loco o bien no era escuchada o bien si lo era, recibía la acogida de una palabra de verdad. O bien caía en el olvido - rechazada tan pronto como era proferida- o bien era descifrada como una razón ingenua o astuta, una razón más razonable que la de las gentes razonables. De todas formas, excluida o secretamente investida por la razón, en un sentido estricto, no existía. A través de sus palabras era como se reconocía la locura del loco; ellas eran el lugar en que se ejercía la separación, pero nunca eran recogidas o escuchadas. Nunca, antes de finales del siglo XVIII, se le había ocurrido a un médico la idea de querer saber lo que decía (cómo se decía, por qué se decía) en estas palabras que, sin embargo, originaban la diferencia. Todo ese inmenso discurso del loco regresaba al ruido; y no se le concedía la palabra más que simbólicamente, en el teatro en que se le exponía, desarmado y reconciliado, puesto que en él jugaba el papel de verdad enmascarada (14).

Es interesante señalar que justo en la época en que Silvina Ocampo gana visibilidad dentro del campo cultural latinoamericano estaba en auge en Argentina la discusión acerca del lugar que debería ocupar la palabra del loco, gracias a la vigencia de los estudios psicoanalíticos de Freud, que no sólo lograron legitimarla, sino también, como señala Ana Teresa Torres en Historias del continente oscuro (2007), legitimar la palabra de la mujer. Sin embargo, tal legitimación no borró realmente, como señala Foucault, la línea de separación, la segregación; por lo tanto, la distancia hacia ambos 
discursos, el del loco y el de la mujer, sigue existiendo, aunque actualmente esté resignificada.

basta con pensar -sugiere Foucault al respecto- en todo el armazón de saber, a través del cual desciframos esta palabra; basta con pensar en toda la red de instituciones que permite al que sea -médico, psicoanalista- escuchar esa palabra y que permite al mismo tiempo al paciente manifestar, o retener desesperadamente, sus pobres palabras; basta con pensar en todo esto para sospechar que la línea de separación, lejos de borrarse, actúa de otra forma, según líneas diferentes, a través de nuevas instituciones y con efectos que no son los mismos. Y aún cuando el papel del médico no fuese sino el escuchar una palabra al fin libre, la escucha se ejerce siempre manteniendo la cesura. Escucha de un discurso que está investido por el deseo, y que se supone -para su mayor exaltación o para su mayor angustia- cargado de terribles poderes (1992, p. 14).

Al parecer, Ocampo jugó con estos elementos, jugó con ese poder oculto tras la palabra del loco, que en medio del delirio revela terribles verdades, y jugó con la palabra de la mujer, también desestimada dentro de estos órdenes sociales de poder por su afinidad con lo emocional, con lo irracional; como una manera de plantear justamente esa situación de marginalidad. El personaje recurrente de las sonámbulas es expresión de la unión de estas dos cosas; lo interesante es que Ocampo no le otorga la palabra, y es sólo a través de su gesto, de su actitud delirante, que queda expresada su existencia.

Un buen ejemplo de esto lo constituye Aurelia, la sonámbula del cuento "La familia Linio Milagro", presentada por la autora como una mujer que:

no había tejido ninguna tricota; era ella la hermana que provocaba secretos, gritos contenidos dentro de los cuartos cerrados, discusiones terribles a la hora de las comidas, siestas larguísimas en invierno; era ella la causante de los sueños atrasados. ¿Desde cuándo? Desde que empezaba el recuerdo de esas seis hermanas. Aurelia envuelta en gasas de automovilista antigua bajaba las escaleras a las cuatro de la mañana, encendía todas las luces de la sala y tocaba el piano perpendicular, con los pedales incesantes arrastrando las notas. Espaciosos misterios cubrían esa música nocturna que se despertaba en el sueño de Aurelia y en los desvelos de sus hermanas (1999, p. 54).

Es el sonido de este piano el que ocupa entonces el lugar de la palabra: una "música nocturna" que se despierta en el sueño y que irrumpe, desde 
ese otro lugar de enunciación, como contenido liberado de la forma que esa palabra impone, de la identidad que presupone el asumir su pronunciación, su articulación con el mundo. Una palabra que, además, al no estar legitimada, no existe; y por ello es esa no existencia la que impone, esa condena al secreto, a los "gritos contenidos dentro de los cuartos cerrados". Por eso es "la causante de los sueños atrasados".

Mientras que la música con la que se expresa Aurelia recuerda esa "pura materia sonora intensa en relación siempre con su propia abolición", a la que se refieren Deleuze y Guattari, "sonido musical desterritorializado, grito que escapa a la significación, a la composición, al canto, al habla, sonoridad en posición de ruptura para desprenderse de una cadena todavía demasiado significante" (1987, p. 15).

En ese sentido, puede considerarse el comportamiento de Aurelia como un acto de liberación ante cualquier imposición identitaria, vinculado con lo que los mismos autores explican como proceso o agenciamiento del devenir-animal:

Devenir-animal consiste precisamente en hacer el movimiento, trazar la línea de fuga en toda su positividad, traspasar un umbral, alcanzar un continuo de intensidades que no valen ya por sí mismas, encontrar un mundo de intensidades puras en donde se deshacen todas las formas, y todas las significaciones, significantes y significados, para que pueda aparecer una materia no formada, flujos desterritorializados, signos asignificantes (1987, p. 24).

Un proceso del que varios de los personajes de Ocampo son agentes, al traducir por medio de sus gestos las rupturas presentes en la escritura que los $\mathrm{crea}^{2}$, las escisiones por las que se cuelan esas "intensidades puras" que no pueden ser contenidas por categorías establecidas, que se pronuncian en busca de su propia forma.

Esta actitud innegable pero a la vez ininteligible de la sonámbula genera miedo en su entorno. La familia -reino patriarcal por excelencia- siente que hay algo oculto en Aurelia y, por temor, se ve en la necesidad, o mejor ante la exigencia de dejarla actuar, sin poder normatizar ninguna acción,

\footnotetext{
${ }^{2}$ En este sentido, es interesante recordar las palabras de Edgardo Cosarinsky, expuestas en su prólogo a la antología de Informe del cielo y del infierno, donde refiere ciertos rasgos que caracterizan la escritura de Silvina: "ese tono reconocible y sin embargo nada monocorde, capaz de variaciones y distintos registros, que las palabras difícilmente pueden fijar, que más bien pueden sólo circundar, como si se refirieran a una música" (1970, p. 7).
} 
por más absurda que parezca. Sólo una vez las hermanas intentan cerrar el piano para evitar que se cuele esa música inquietante, pero Aurelia no soporta tal confinamiento y termina "tendida en el suelo con las manos ensangrentadas de espejos rotos, los ojos cerrados". Aurelia rompe los espejos porque no es capaz de vivir entre formas impuestas desde afuera de sí misma. Las hermanas entonces deciden dejar abierto el piano. Ante tal circunstancia, se evidencia además una insuficiencia legal y lingüística por parte de la familia, pues ni la ley ni la palabra pueden contener esas "corrientes remotas de música" que llegan incluso a traspasar el cuerpo de Aurelia, a someterlo a una pasión que termina por borrarlo:

Aurelia no estaba en ninguna parte, sólo el piano se oía, apagándose con el fuego creciente. Aurelia no se salvó del incendio. Envuelta en sus gasas de automovilista antigua, murió como Juana de Arco, oyendo voces. La familia Linio Milagro, perseguida por el piano de las cuatro de la mañana, se mudó infinitas veces de casa (Ocampo, 1999, p. 55).

Esta mujer, esta sonámbula que se deja arrastrar por un mar de emociones que alude a conexiones instintivas, quien con su música viene a quebrar todas las formas convencionales establecidas, termina por consumirse en el incendio de su propia pasión ${ }^{3}$ ya que no encuentra lugar en este mundo. Ese gesto constituye una "línea de fuga", una ruptura que abre paso a esa "materia no formada", a esos "flujos desterritorializados", a esos "signos asignificantes" capaces de desestabilizar la lógica e indicar la presencia de una identidad construida al margen de la sujeción al lenguaje o a cualquier otra institución.

Esta postura de Ocampo se refuerza en otras de sus ficciones y adquiere matices interesantes en las sonámbulas protagonistas de otros cuentos. En "El pasaporte perdido", por ejemplo, se presenta el personaje, que luego terminará asociado a la sonámbula, a partir de una pregunta explícita que al mismo tiempo parecen hacerse la protagonista -Claude Vildrac, una niña de 14 años que viaja sola en barco por primera vez y que adquiere su identidad a partir de los datos recogidos en su pasaporte ${ }^{4}$ - y la voz que narra:

${ }^{3}$ Es interesante que Ocampo sugiera que el incendio en el que Aurelia muere posiblemente haya sido provocado por alguno de sus familiares para tratar de obtener los beneficios del seguro, pues la casa donde vivían ya estaba muy vieja. El cuestionamiento en este caso estaría orientado hacia las nociones de "ley" y de "transgresión" como puntos de partida para pensar la confrontación entre Aurelia y la familia.

${ }^{4}$ Así comienza este cuento, ofreciendo al lector la descripción que de la protagonista nos da su pasaporte; rasgos que definen su identidad: "Certifico que Da. Claude Vildrac, de estado soltera, de profesión..., que sí lee y escribe, y cuya fotografía, impresión digitopulgar derecha y firma

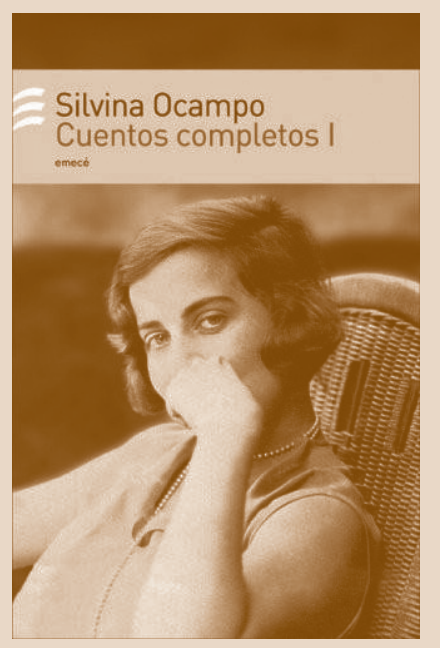


¿Quién era Elvia? No sabía su apellido, no sabía quién era su padre ni su madre, y, sin embargo, Elvia era la persona a quien ella seguía a bordo todo el día; era la persona a quien daría su salvavidas el día del naufragio (Ocampo, 1999, p. 19).

La respuesta, en contraste con la descripción de Claude recogida en su pasaporte, que la sitúa como sujeto social en medio de ataduras identitarias que le otorgan existencia y le adjudican una apariencia y una pertenencia determinadas, perfila un personaje sin más identidad que el enigma de su presencia, una mujer que ejerce una gran atracción sobre la niña al proponerse como subjetividad femenina no sometida a la sujeción; la única a quien, según Claude, valdría la pena salvar. Pero no es así como piensan los demás.

En este cuento, Ocampo muestra de nuevo cómo la sociedad reacciona con temor y desprecio ante aquello que no puede someter a sus parámetros, e inmediatamente se protege adjudicando categorías que sitúan lo que inquieta y perturba en lugar conocido:

¿Quién era Elvia? "Una guaranga”, decían "algunos". "Una mujer de la vida", había dicho un viejo, tapándose la boca, como si tosiera, al ver el cabello suelto y las piernas rasguñadas de Claude (Ocampo, 1999, p. 19).

Pero estas categorizaciones no afectan a Claude, porque ella, como niña que apenas comienza a entrar en la adolescencia, no las conoce. Desde su inocencia, ella las entiende a su modo, e incluso ni siquiera así le parece que encajan con Elvia.

"Una mujer de la vida" debería tener un traje negro de trabajadora, con grandes remiendos y zapatos gastados de caminar por la vida. Así veía Claude a "las mujeres de la vida", con la boca despintada y una gran bolsa en las espaldas, como los linyeras, caminando de estancia en estancia (Ocampo, 1999, p. 19).

Esto permite, como se anunciaba al principio, repensar el vínculo entre palabra e identidad, pues si bien en el caso de Aurelia se establece como

figuran al dorso, es nacida... 15 de abril de 1922... en el pueblo... Cap. Federal, Buenos Aires, Rep. Argentina... tiene $1 \mathrm{~m} 40 \mathrm{~cm}$ de altura, el cutis de color blanco, cabello rubio, nariz de dorso recto, boca med. y orejas med.....

Claude seguía las huellas de su cara con las dos manos y mirando el pasaporte pensaba: 'No tengo que perder este pasaporte. Soy Claude Vildrac y tengo 14 años. No tengo que olvidarme; si pierdo este pasaporte ya nadie me reconocería, ni yo misma"' (Silvina Ocampo, 1999, p. 17). 
ruptura a partir de la sustitución de la palabra por la música, es decir, por un sonido o signo asignificante que escapa a toda forma; en el caso de Elvia se crea, en principio, a partir de lo que "el otro" impone como marca distintiva a través de la palabra; pero luego es precisamente esta imposición la que Claude parece neutralizar, e incluso quebrar cuando, libre de otra connotación por no haberla aprendido aún, le asigna un significado distinto a partir de lo que para ella quieren decir esas mismas palabras, es decir, a partir de su experiencia; lo que implica un acercamiento entre ambas mujeres que de ninguna manera puede darse a partir de la asignación de una categoría identitaria. Esto queda así expresado en el cuento:

Claude recordaba una mañana en que, corriendo por el decktennis, se había caído al suelo. Elvia la había recogido con un gesto maternal y le había vendado la rodilla lastimada con un pañuelo fino. Después, cuando se encontró sola, vio que la esquinita del pañuelo llevaba un nombre bordado: Elvia. Así había conocido a Elvia. Recostó su cabeza contra la frescura blanda de la almohada; las almohadas eran caracoles blancos donde se oye de noche el ruido del mar, sin necesidad de estar embarcada. Lo que más le gustaba de a bordo eran los desayunos por las mañanas, la música de circo, el miedo de los naufragios y Elvia (Ocampo, 1999, p. 19).

Evidentemente, Claude es la única que ve a Elvia sin juzgarla, como los demás. Su aproximación es más visual que lingüística y eso permite que las identidades se aproximen sin conocerse del todo. Sin duda, esto constituye una manera de cuestionar la realidad de las convenciones, de desterritorializarlas al someterlas a una mirada desde afuera que problematiza no sólo la convención en sí, sino también las convenciones en torno de "lo otro", "el otro" contenidas en las formas de comunicación tradicionales.

De esta manera, Ocampo parece querer mostrar cómo toda convención acerca de lo femenino -lo que se le estampa, la imagen que se ve "desde el otro", lo que se le atribuye- termina por situar a la mujer en un espacio predeterminado, asignado, pero ambiguo al mismo tiempo -tal y como sucede, según Foucault, con la palabra del loco-, porque aquello que es su experiencia debe quedar silenciado en ese lugar, debe quedar excluido, ahogado como los gritos de las hermanas de Aurelia; y si de alguna manera se manifiesta, inmediatamente arrastrará a la mujer hacia otras categorías que, como en el caso de "loca" o "delirante", "guaranga" o "mujer de la vida", servirán para neutralizar los peligros que comporta su discurso, y también su gesto. Pero eso no quiere decir que el discurso no exista, aun cuando

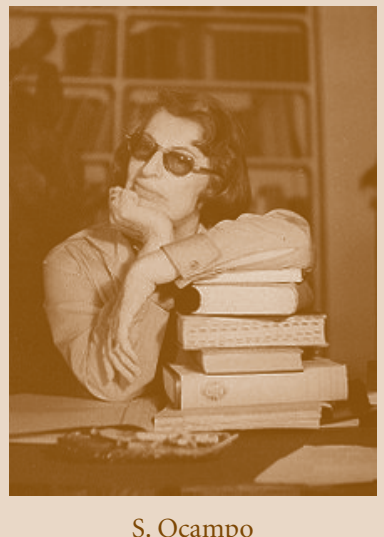

S. Ocampo 
deje de ser discurso y devenga música. Esas categorías lo que hacen es marcar un límite que hacia adentro del sistema social establecido proyecta una imagen, tal y como lo haría un espejo, pero que no se corresponde, y en este caso mucho menos, con lo que queda detrás, informe, en movimiento; tal y como puede ser pensado, con respecto a la vigilia, el ámbito de lo onírico. De ahí la recurrencia del personaje de la sonámbula en los cuentos de Ocampo, como expresión de aquella mujer que se mueve impulsada por un flujo que, como en el caso de Aurelia, nace del sueño. Y de ahí que también en "El pasaporte perdido" Elvia termine asociada a la sonámbula que Claude vio dibujada en el plato del restaurante donde almorzó con su familia antes de embarcar; o, dicho de otro modo, asociada a una imagen evocadora cuya identidad no está sujeta a ninguna palabra.

Para afianzar su propuesta del ser sin sujeción, esta autora se vale del humor y la ironía como estrategias retóricas que configuran un punto de vista narrativo ajeno a las convenciones, lo que ya supone una primera vía para el cuestionamiento.

Por otra parte, a la ironía, al humor, se une en muchos casos la identidad infantil, porque el niño mantiene esa mirada todavía libre de convenciones y elaboraciones sociales que revela las cosas tal cual son. Cosarinsky comenta, en este sentido, que la "utilidad literaria [de los niños en los cuentos de Silvina Ocampo] es, siempre, la de provocar, como una mirada fingidamente ingenua, que al mismo tiempo reconoce $y$, por su misma impasibilidad, hace terrible lo que reconoce, numerosos, incalculables ecos" (Cosarinsky, 1970, p. 13).

Estos son algunos de los elementos que hacen que la escritura de Silvina Ocampo sea catalogada usualmente de vanguardista, porque ella busca con insistencia y hasta con cierta insolencia rebelde quebrar los estereotipos de una sociedad que se presenta descompuesta. Para ello, deja al descubierto la subjetividad como categoría, su condición de máscara y el inmenso vacío, la desgarradora ausencia que hay detrás. Busca quebrar la forma, valiéndose de la resonancia de los ecos, para abrir nuevos espacios. Habla de realidades a través de la ficción, y entremezcla de tal manera ambos lados del espejo que el lector llega a perder la certeza de cuál es cada uno.

Esa ambigüedad otorga un espacio propicio para la mención de los aspectos terribles y crueles de la sociedad y del individuo, sin que estos sean percibidos como una amenaza real, a pesar de -o justamente por-generar muchas veces un profundo desconcierto en el lector.

Esta ambigüedad se establece no sólo entre lo real y lo irreal, como se ha visto hasta ahora, sino también entre lo real y lo literario, donde entra en juego la estética. Hay varios pasajes en los cuentos de Ocampo que parecen 
involucrar al lector a través de una complicidad particular que establece la narración, como en "Los objetos", un cuento cuyo argumento gira en torno a la recuperación asombrosa e inesperada, por parte de la protagonista, de juguetes que había perdido en la infancia.

Del modo más natural para ella y más increíble para nosotros, fue recuperando paulatinamente los objetos que durante tanto tiempo habían morado en su memoria. Simultáneamente advirtió que la felicidad que había sentido al principio se transformaba en malestar, en un temor, en una preocupación. Apenas miraba las cosas, de miedo de descubrir un objeto perdido. Desde la estatua de bronce con la antorcha que iluminaba la entrada de la casa, hasta el dije con el corazón atravesado con una flecha, mientras Camila se inquietaba, tratando de pensar en otras cosas, en los mercados, en las tiendas, en los hoteles, en cualquier parte, los objetos aparecieron. La muñeca cíngara y el calidoscopio fueron los últimos. ¿Dónde encontró estos juguetes, que pertenecían a su infancia? Me da vergüenza decirlo, porque ustedes, lectores, pensarán que sólo busco el asombro y que no digo la verdad. Pensarán que los juguetes eran otros parecidos a aquéllos y no los mismos, que forzosamente no existirá una sola muñeca cíngara en el mundo ni un solo calidoscopio. El capricho quiso que el brazo de la muñeca estuviera tatuado con una mariposa en tinta china y que el calidoscopio tuviera, grabado sobre el tubo de cobre, el nombre de Camila Ersky (Ocampo, 1999, p. 181).

Sin embargo, la complicidad no se da, como podría esperarse, en relación al hecho sorprendente que está siendo narrado -es decir, la complicidad no parte del hallazgo insólito de objetos perdidos años atrás-, sino que se fundamenta en la estética del cuento, en su confección: "Si no fuera tan patética, esta historia resultaría tediosa. Si no les parece patética, lectores, por lo menos es breve, y contarla me servirá de ejercicio" (Ocampo, 1999, p. 182).

Este comentario revela un nuevo aspecto desconcertante: Ocampo relativiza lo asombroso, lo aparentemente sobrenatural, lo fantástico verosímil de su obra y deja al descubierto el proceso de confección de la misma. Al decir "todo esto no es más que una invención", la escritura en sí está siendo legitimada. De pronto, lo sobrenatural que sorprende -o, al menos, debería sorprender- pasa a ser el resultado de un ejercicio de construcción estética ${ }^{5}$.

\footnotetext{
${ }^{5}$ Este planteamiento pudiera vincularse con esa idea borgiana del soñador que es soñado, aunque con un sutil desplazamiento. En el caso de Borges, esta situación termina siempre por ser revelada como realidad de lo contado; mientras que en Silvina, se revela como una construcción que tiene lugar dentro de la estética de la literatura, a partir de la escritura.
} 
Precisamente aquí se anclan los versos que sirven de epígrafe a este trabajo. La obra de Silvina Ocampo sólo entrega su realidad a quien la busca, hurgando, en el silencio de entrelíneas o en el silencio siempre abierto del final. Lo que ella quiere comunicar está encubierto, enmascarado, sólo en las rupturas se abren los espacios, las rendijas por donde se cuela su silencio. Ese silencio es justamente la expresión más fiel del enigma. Si todo es una máscara, ¿qué hay detrás de la máscara? Si todo es imagen reflejada en un espejo, ¿qué hay detrás del espejo? Estas preguntas conectan la propuesta identitaria de Ocampo con aquello que Freud (1974) llamó "lo siniestro", esa cara de la realidad que aparece repentinamente generando desconcierto, estupor. Y más aún se relaciona una cosa con la otra si se considera que Freud entiende la estética como la "ciencia de las cualidades de nuestra sensibilidad". Se trata de una manera de leer el mundo, pero no a partir de la razón, ámbito masculino, sino a partir de la percepción sensorial, la intuición, la emoción o, lo que es lo mismo, desde el ámbito femenino por excelencia, ese que da miedo por su potencia, ese cuyo poder debe ser controlado, confinado, domesticado.

Silvina Ocampo parece entonces utilizar el recurso estético para armar toda una visión del mundo, toda una manera de percibirlo que permita la conexión entre lo visible y lo invisible, entre lo heimlich (familiar) y lo unheimlich (lo oculto), pero asegurándose de decir de vez en cuando: "todo esto no es cierto, es una invención”. De nuevo la ambigüedad, la paradoja. Porque si para Freud (1974) lo siniestro no es "realmente nada nuevo, sino más bien algo que siempre fue familiar a la vida psíquica y que sólo se tornó extraño mediante el proceso de represión", sólo se hace necesario abrir esos espacios por donde pueda colarse aquello que ya desde antes nos pertenece; lo cual también sirve para explicar el hecho de que la significación de la palabra se confunda, se entremezcle con su sentido contrario en un solo término. ¿No es fácil relacionar esto con las dos caras del espejo?

Se podría pensar entonces que Ocampo intenta armar con su escritura, a partir de un recurso estético, un escenario donde ambos sentidos puedan aparecer, planteando así el enigma de nuestras dos caras, la visible y familiar, y la invisible y oculta. Juego de espejos que interpela al lector para que se constituya como sujeto frente a esa realidad integral a la que pertenece ${ }^{6}$.

\footnotetext{
${ }^{6}$ Ana D’Angelo, en su artículo “La experiencia de la corporalidad en imágenes. Percepción del mundo, producción de sentidos y subjetividad", expone que: "los efectos corporales nunca dejan de ser imaginados: no sólo porque responden a imágenes sino porque co-responden a la capacidad de imaginar empáticamente un dolor que no se vivió jamás en el propio cuerpo, pero
} 
Ocampo parece estarle preguntando constantemente al lector: “ $i$ Te parece que es así?" "¿Crees en esto?”. De esta manera, la construcción literaria se convierte en una forma de crear realidades y mundos indefinidamente, desde adentro y desde afuera, desde quien escribe y desde quien lee; y, de la misma manera, sirve para revelar que toda forma de realidad es una construcción, una abstracción, un imaginario, una máscara, y que tal vez lo más real de la realidad sea aquello que permanece siempre intacto, oculto, sin nombre ni voz.

En un ensayo escrito por Manuel Lozano (2002), que se titula "El enigma Silvina Ocampo: la paradoja y lo sublime", encontramos lo siguiente:

el "enigma" nos somete de inmediato a la gravitación de lo imposible ¿Y qué representa "lo imposible", sino un evidente e irreprimible espacio de la ausencia, una narración del mundo, una ausencia del mundo, pero también una reconstrucción sobre sus escombros? El enigma inaugura siempre el espacio de lo conjetural, una vastísima topografía (indisoluble del tiempo) en que la ambigüedad es su ley, pero también su controversia ${ }^{7}$.

A partir de eso es posible decir que, si bien es verdad que Ocampo parece arrastrar todo lo que narra hacia una suerte de desrealización, desaparición, destrucción, también es cierto que lo hace como única manera de abrir nuevos caminos, nuevas posibilidades de realidad dentro de la ambigüedad. Sería una suerte de recorrido contraépico, donde la realización de la identidad tiene lugar cuando desvanece todo lo que ha transcurrido y cuando estos seres sin sujeción emergen al retraer el tiempo.

A pesar de la transgresión, históricamente cuestionable cuando proviene de un sujeto femenino, esta escritura, este proyecto creador, le permite a la autora ingresar en el canon literario latinoamericano, es decir, ser re-

que es sólo imaginable en la medida en que se comparte un mundo de significados y de sentidos (Didi-Huberman, 1997). Sentidos y sentimientos ya que «sentir nunca se da sin que se pongan en juego significados» (Le Breton, 2007, p. 16). Es necesario entonces pensar esta relación en términos intersubjetivos: «reconocer la corporalidad de nuestro ser-en-el-mundo es descubrir un sustrato común donde yo y el otro somos uno»" (D’Angelo, 2010, pp. 235-251). A partir de ello, se evidencia cómo el objeto que ve e interpela puede construir más de un espacio identitario en coexistencia con el del sujeto que se posiciona frente a él.

${ }^{7}$ En http://www.eldigoras.com/eom/2002/tierra08mlz08.htm 
conocida por el campo cultural $^{8}$ del continente. Sirviéndose de todas las estrategias mencionadas, y aunque parezca paradójico, Ocampo construye una ausencia, su propia ausencia, delatando el juego de máscaras dentro del cual se introduce luego de haber confeccionado la suya, la de la ficción literaria.

Esta intención de arrastrar todo hacia el enigma no se limita únicamente a su obra, sino que también se encuentra en ella como sujeto literario, lo que otorga mayor coherencia a su proyecto creador $\mathrm{y}$, al mismo tiempo, lo hace más paradójico, porque plantea la pregunta: ¿es su obra realmente una invención literaria? Son varias las entrevistas en las que Ocampo se presenta como una mujer enigmática que rehuye las preguntas escabulléndose hacia respuestas inestables. Una de ellas es la de María Moreno (2005), "Frente al espejo", donde la entrevistadora comenta al inicio lo siguiente: "Mi admiración por Silvina Ocampo se debía más a sus mitologías que a su calidad literaria", lo cual, al parecer, alude directamente a ese desconcierto que genera en el lector-acostumbrado a las construcciones ordenadas, lógicas, racionales legitimadas por el canon- una escritura tan desgarrada, $\tan$ fragmentada ${ }^{10}$.

A partir de ahí, continúa Moreno relatando distintos encuentros con la escritora en los que siempre sucedía algo extraordinario, como un día en el que Silvina se tardó en abrir la puerta y luego se disculpó diciendo: "No escuché el timbre. En esta casa los sonidos son tan bajos como las voces que escuchaba Juana de Arco. Deben ser las cucarachas las que ensordecen el timbre." Y al rato, luego de haber dejado a su interlocutora reflexionando sobre las cucarachas, le dijo, en voz baja: "La cucaracha es el Ser". En otra entrevista, realizada por Raúl Gálvez ${ }^{11}$, sucede lo mismo. Es curioso, pero en ambos casos la entrevista comparte su espacio de preguntas con el relato

\footnotetext{
${ }^{8}$ Ocampo fue merecedora de muchos premios: Premio Municipal por Espacios métricos (poesía) en 1954, Segundo Premio Nacional de Poesía por Los nombres en 1953, Premio Nacional de Poesía por Lo amargo por dulce en 1962, y el Premio del Club de los 13 por Cornelia frente al espejo en 1988. html

${ }^{9}$ En Página 12: http://www.pagina12.com.ar/diario/suplementos/radar/9-2558-2005-10-11.

${ }^{10}$ Esta autora no es la única en formular esta observación. Enrique Anderson Imbert, en su Historia de la literatura hispanoamericana, también señala algo parecido: "Fue más innovadora en sus cuentos fantásticos de Viaje olvidado (1937) y Autobiografía de Irene (1948), en los que el lirismo, a veces de raíz metafísica, conmueve con su desnuda presencia, aunque la autora suela descuidarse en la composición narrativa" (1957, p. 405).

${ }^{11}$ Entrevista realizada en 1987 para Idea Viva y publicada en el libro del mismo autor titulado From the Ashes Land of Virgin. Toronto: Mosaic Press, 1990.
} 
anecdótico del encuentro singular entre el entrevistador y la escritora, y deja en quien las lee la sensación de un cierto sobrecogimiento emanado de la presencia de esta mujer.

¿Estrategia o autenticidad? En la primera de las entrevistas, dice Silvina: "ser sincero es ser potente". He aquí, justamente, el juego. Raúl Galvéz dice, por su parte: "A Silvina no sólo no le gustan las entrevistas, sino que en realidad tampoco le gusta hablar. [...] Lo que a Silvina le gusta... es jugar. Jugar verbalmente. Jugar con los temas de conversación, y jugar con la percepción de la realidad”. Esto dialoga directamente con lo dicho por María Moreno en su entrevista: "El giro absurdo tomado por algunas preguntas parece no desconcertarla sino más bien satisfacer su deseo de seducción." Porque es así como todo termina en ese espacio paradójico, que tiene algo del absurdo cósmico de Macedonio Fernández.

Es tal la ambigüedad que envuelve sus textos, y que la envuelve a ella como escritora, como subjetividad, que la línea entre realidad y fantasía se borra, y tanto lector como entrevistador, como se ha dicho, quedan atrapados en esa red invisible de significaciones que trascienden lo posible abriendo espacios para que irrumpa lo inesperado, "lo siniestro" 12 , lo mágico, lo terrible, de la misma manera en que aparece la mariposa sobre el mar, buscando los ojos de Keng-Su, quien sólo atina a decir, en otro idioma: "Ahí está. Es ella" (Ocampo, 1999, p. 69), mientras señala una ausencia, la amenaza de un fantasma.

Hoy en día, dentro del ámbito de la teoría literaria de géneros, se sigue hablando de ausencia en relación al sujeto femenino en el discurso, es decir, dentro de las instancias de poder. Lugones ${ }^{13}$ lo señala al hablar de la necesidad de articular símbolos que representen a la mujer, sin traicionarla, dentro de ese mundo concreto que está pensado a partir de un imaginario, de una abstracción, donde la mujer no se encuentra. Abstracción y ausencia de las que también habla Lola Luna en su texto Leyendo como mujer la imagen de la mujer (1996). Ludmer (1984), por su parte, propone estrategias para insertarse en el mundo sin abandonar los espacios propios de la mujer, es decir, sin tener que introducirse en esos espacios de poder fijados por lo

\footnotetext{
${ }^{12}$ Se sigue aquí lo expresado por Freud en "Lo siniestro", en Obras completas. Vol. VII. Madrid: Biblioteca Nueva, 1974 (fecha de publicación del texto original en alemán, 1919).

${ }^{13}$ En su introducción a La sartén por el mango, Patricia Elena González hace el siguiente comentario: "María Lugones proponía la construcción y creación (¿o reconstrucción?) de cánones femeninos desde el descubrimiento y la identificación de uno misma. Sus comentarios conducían al diálogo por caminos pioneros, difíciles, y hasta nos invitó a quemar las naves en pro de una forzada separación" (1984: 14).
} 
masculino para cuestionarlos y transformarlos; de manera de lograr que estos se abran a los de la mujer y los incluyan.

Estos rasgos pueden encontrarse en la obra de Silvina Ocampo como estrategias de inserción en el canon literario de su época y, sobre todo, como problemas planteados ya desde entonces. La articulación de la ausencia, los espacios de lo femenino insertos en la escritura. Incluso el género fantástico es llevado o trabajado desde espacios de escritura femenina, como la anécdota, la autobiografía, la experiencia de una primera persona. Y los temas tratados siempre aluden también al mundo de la mujer.

Finalmente, Ana Teresa Torres, en sus recientes ensayos sobre la condición femenina, también parece coincidir de algún modo con la propuesta de Ocampo -en cuya ficción hay un evidente intento de teorización en torno a la identidad-, no sólo por defender el silencio como espacio donde se refugia aquello de la mujer "que no le ha sido arrebatado, domesticado, subordinado" (Torres, 2007, p. 272), sino por proponer un vaciamiento que permita partir desde esa ausencia que constituye al sujeto femenino dentro de nuestro imaginario convencional, literario, teórico. "A la hora de establecer pautas o conceptos-sugiere Torres- para construir el sujeto femenino, rescato el valor del silencio, el respeto por el vaciamiento de la mitología femenina" (Torres, 2007, p. 274).

Al silencio llegan y del silencio parten todas las palabras de Silvina; en la narrativa, en la poesía, en la sencilla conversación. Tal vez ese misterio, esa ausencia de sentido haya sido el elemento de juego, de seducción, que permitió su ingreso al canon, su reconocimiento dentro del campo literario como escritora editada, reeditada y muchas veces premiada; esa ausencia de sentido que, sin embargo, parece llenar todo de sentido; ese vacío reclamando contenido, oculto tras la inofensiva máscara de la invención. Pura presencia en donde la palabra, la identidad, desaparecen.

La vida propone señales en todas partes, sólo que la gente no permanece atenta.

Escribo porque no me gusta hablar, para dejar un testimonio más de la vida o para luchar contra ese exceso de materia que acostumbra a rodearnos...

Silvina Ocampo. En Moreno (2005). 


\section{REFERENCIAS}

Anderson Imbert, E. (1957). Historia de la literatura hispanoamericana. México D.F.: Fondo de Cultura Económica.

Cosarinsky, E. (1970). "Prólogo", en Ocampo, S. Informe del cielo y del infierno. Antología. Caracas: Monte Ávila Editores.

D’Angelo, A. (2010). "La experiencia de la corporalidad en imágenes, percepción del mundo, producción de sentidos y subjetividad”. Tabula Rasa, 13, 235-251.

Deleuze, G. y Guattari, F. (1987). Kafka Por una literatura menor. México D.F: Biblioteca Era.

Elejabeitia, C. (1987). Liberalismo, marxismo y feminismo. Barcelona: Anthropos.

Foucault, M. (1992). El orden del discurso. Barcelona: Tusquets.

Freud, S. (1974). "Lo siniestro”, en Obras completas, Vol. VII. Madrid: Biblioteca Nueva (fecha de publicación del texto original en alemán, 1919).

Lozano, M. (2002). "El enigma Silvina Ocampo: la paradoja y lo sublime”. Publicado en http://www.eldigoras.com/eom/2002/tierra08mlz08.htm el 8 de febrero de 2002. (Visitada el 21 de enero de 2012).

Ludmer, J. (1984). "Las tretas del débil”, en González, Patricia Elena y Eliana Ortega (eds.) La sartén por el mango (pp.47-55). Río Piedras: Huracán.

Luna, L. (1996). Leyendo como una mujer la imagen de la mujer. Barcelona: Anthropos.

Moreno, M. (2005). “Frente al espejo”. Publicado en Página 12: http://www. pagina12.com.ar/diario/suplementos/radar/9-2558-2005-10-11.html el 5 de octubre de 2005. (Visitada el 21 de enero de 2012).

Ocampo, S. (1970). Informe del cielo y del infierno. Antología. Caracas: Monte Ávila Editores.

Ocampo, S. (1999). Cuentos completos. Buenos Aires: Emecé Editores.

Torres, A. T. (2007). Historias del continente oscuro. Caracas: Editorial Alfa. 